\title{
Left Atrial Appendage Mechanical Changes in Patient with Mitral Stenosis Speckle Tracking Imaging Study
}

\author{
Mahmoud Kamel*, Ahmed Emara, Said Shalaby, Sahar Hantour \\ Department of Cardiology, Menoufia University, Menoufia City, Egypt \\ Email: *mahmoudkamel35@gmail.com, magmoud.gabr@med.menofia.edu.eg, am.emara@yahoo.com, \\ saidshalaby@yahoo.com, sahar55@yahoo.com
}

How to cite this paper: Kamel, M., Emara, A., Shalaby, S. and Hantour, S. (2019) Left Atrial Appendage Mechanical Changes in Patient with Mitral Stenosis Speckle Tracking Imaging Study. World Journal of Cardiovascular Diseases, 9, 20-30.

https://doi.org/10.4236/wjcd.2019.91003

Received: December 17, 2018

Accepted: January 19, 2019

Published: January 22, 2019

Copyright () 2019 by author(s) and Scientific Research Publishing Inc. This work is licensed under the Creative Commons Attribution International License (CC BY 4.0).

http://creativecommons.org/licenses/by/4.0/

\begin{abstract}
Background: LAA is the major site of thrombus formation in mitral stenosis; active LAA blood flow and contractile function may be disturbed in MS. TEE is the modality of choice for evaluating LAA and Speckle-tracking echocardiography (STE) is a recently developed technique for the characterization and quantification of myocardial deformation. It permits measurement of LA and LAA strain and strain rate which can be used to assess the mechanical function of LAA. Objective: To assess the mechanical function of left atrial appendage (LAA) in mitral stenosis (MS) patients with sinus rhythm by $2 \mathrm{D}$ speckle tracking strain and strain rate through transesophageal echocardiography (TEE). Patients \& Method: Thirty-three patients with moderate to severe MS and sinus rhythm, $38.33 \pm 5.66$ years as a case group and twenty-two age and sex matched healthy volunteers as a control group. All participants underwent compete conventional transthoracic echocardiography; TEE for assessment of LAA morphology and Doppler flow and speckle tracking strain \& strain rate were measured from LAA walls. Results. LAA Doppler flow peak velocities, LAA strain, reservoir strain rate (RSr), conduit strain rate $(\mathrm{CSr})$ and atrial contractile strain rate (ASr) all were significantly lower in patient group. Global Strain of LAA had a negative correlation with LA diameter, pulmonary artery systolic pressure \& degree of spontaneous echo contrast and a positive correlation with MS area and LAA Doppler flow. Conclusion: 2D speckle tracking strain and strain rate of LAA is a feasible technique and is significantly reduced in patients with mitral stenosis even with sinus rhythm.
\end{abstract}

\section{Keywords}

LAA, Mitral Stenosis, 2D Speckle Tracking Strain and Strain Rate 


\section{Introduction}

The left atrial appendage LAA has unique developmental, functional and anatomical properties. These properties make it ideal to act as a reservoir in conditions of volume overload, and to affect the adaptive compensatory mechanisms necessary for the reduction of circulating blood volume. The LAA is the most frequent site of thrombus formation in atrial fibrillation and to a lesser extent in mitral valve disease [1]. Although AF is the most common cause of thrombus formation inside LAA, many patients with sinus rhythm also can develop thrombi inside the LAA [2] [3]. In patients with mitral stenosis, active left atrial appendage blood flow and contractile function may be disturbed. This may be due to the significant increase in left atrial pressure caused by after load elevation. Left atrial appendage contractile dysfunction may lead to blood stasis in the LAA cavity and this may be one of the mechanisms responsible for formation of spontaneous echo contrast and thrombus in LAA [1]. Echocardiography, particularly trans-esophageal echocardiography (TEE), is currently the modality of choice for assessment of the LAA. It allows complete delineation of the LAA anatomic details in almost all patients and, at the same time, also permits a comprehensive assessment of its function [4]. Speckle-tracking echocardiography (STE) is a recent technique for the quantification and characterization of myocardial deformation [5]. It permits measurement of LA \& LAA strain and strain rate which can be used to assess the mechanical function of LAA adequately [5].

The study aims to assess the mechanical function of LAA in patients with mitral stenosis and sinus rhythmby $2 \mathrm{D}$ speckle tracking strain and strain rate through transesophageal echocardiography.

\section{Patients and Methods}

The study included 55 individuals, thirty three patients with mitral stenosis and sinus rhythm as a patients group and twenty two age and sex matched healthy volunteers as a control group. They enrolled in the study after obtaining their written informed consent, and approval of Ethics Committee of Menoufia University.

All participants were subjected to full history taking, complete clinical examination, resting 12-lead surface ECG, Conventional echocardiographic examination was done using the commercially available Vivid 9, GE Vingmed, Norway equipped with a $1.7-4 \mathrm{MHz}$ phased-array transducer. LV dimensions, volumes, ejection fraction, aortic root \&left atrium diameters, mitral valve morphology and Doppler parameters and Pulmonary artery systolic pressure were measured, Transesophageal echocardiography for assessment of left atrial appendage morphology, smallest \& largest areas, ejection fraction and Doppler flow velocities: emptying (positive waves) and filling (negative waves).

For measurement of LAA longitudinal strain and strain rate, two dimensional images from mid esophageal two-chamber view were recorded, at least three 
cardiac cycles were digitally stored for off-line analysis on a personal computer (PC) workstation using custom analysis software (Echopac PC, Version 110, GE Healthcare). Stored images were applied to automated Cardiac Motion Quantification program. We traced the medial wall from the beginning of the medial part of LAA opening to the lower point of medial wall at the apex of LAA and the lateral wall from the beginning lateral part of LAA opening to the lower point of lateral wall at the apex of LAA. The software then created a region-of-interest (ROI) which included the entire myocardial thickness. The ROI was adjusted manually until a satisfactory image was obtained then tracked the myocardial speckles frame by frame and generated moving images displaying the tracking.

After approval of the ROI, the strain(S) and strain rate (SR) are calculated over the cardiac cycle. Longitudinal strain and strain rate were assessed in the medial and lateral LAAwalls. The average value of strain (\%) at each wall was obtained by averaging of its 3 segments (basal, mid \& apical) and the global LAA strain was obtained by averaging the strain values of 6 LAA segments.

Reservoir Strain rate (RSr), conduit Strain rate (CSr) and atrial contractile Strain rate (ASr) at each wall (medial \& lateral) and global LAA strain rate were obtained.

\section{Statistical Analysis}

Data were analyzed using SPSS software. Quantitative data expressed as mean and standard deviation Chi-square test student test, Mann whiney U test, Kruskal Walls test and correlation coefficient test.

\section{Results}

The current study included thirty three patients, with mitral stenosis, (patients group) recruited from cardiac outpatient clinic of Cardiology department Menoufia University Hospital during the period from June 2015, to June 2017, mean age was $38.33 \pm 5.66$ years, twenty four patients were female constituted $72.4 \%$, while control group included twenty two sex and age matched healthy volunteers with mean age $35.09 \pm 6.73$ years, 15 person were female $(68.2 \%)$ with no significant difference between both groups as regarding age and sex (Table $1)$.

As regarding Conventional echo Doppler parameters, patients group showed higher LA dimension and pulmonary artery systolic pressure (PASP) while the MVA is much smaller in group 1 either by PHT or planimetry (Table 2).

The LAA Doppler flow waves peak velocities are lower in patent group either positive (emptying) or negative (filling) waves also the LAA largest and smallest areas were larger in patient group but with lower EF (46.73 \pm 13.95 vs. $54.22 \pm$ $10.94 \mathrm{p}$ 0.039), three patient in patients group had LAA thrombi, 9 patient (27.3\%) had SEC grade II and 8 patients (24.2\% 0 had grade III) while in control group no one had LAA thrombi or grade II \& III of SEC (Table 3 ). 
Strain of both medial and lateral walls were significantly lower in group I, reservoir strain rate (RSr), conduit strain rate $(\mathrm{CSr})$ and atrial contractile strain rate (ASr) all were significantly lowered in patient group (Table 4; Figures 1-3).

Global Strain of LAA had a negative correlation with LA diameter, PASP \& degree of SEC and had a positive correlation with MVA, LAA filling and emptying Doppler Flow \& LAAEF (Table 5).

Table 1. Comparison of demographic between patients and control groups.

\begin{tabular}{|c|c|c|c|c|c|c|c|}
\hline & & \multicolumn{2}{|c|}{$\begin{array}{c}\text { Group (I) } \\
\mathrm{N}=33\end{array}$} & \multicolumn{2}{|c|}{$\begin{array}{c}\text { Group (II) } \\
\mathrm{N}=22\end{array}$} & t-test & p-value \\
\hline \multirow{2}{*}{\multicolumn{2}{|c|}{ Age (mean \pm S.D) }} & \multicolumn{2}{|c|}{$38.33 \pm 5.66$} & \multicolumn{2}{|c|}{$35.09 \pm 6.73$} & 1.928 & 0.0593 \\
\hline & & $\mathrm{N}$ & $\%$ & $\mathrm{~N}$ & $\%$ & & \\
\hline \multirow[t]{2}{*}{ Sex } & Male & $9 / 33$ & $27.3 \%$ & $7 / 22$ & $31.8 \%$ & 0.333 & 0.564 \\
\hline & Female & $24 / 33$ & $72.7 \%$ & $15 / 22$ & $68.2 \%$ & & \\
\hline HR (r & \pm S.D) & \multicolumn{2}{|c|}{$81.70 \pm 15.85$} & \multicolumn{2}{|c|}{$80.23 \pm 14.69$} & 0.120 & 0.730 \\
\hline
\end{tabular}

Table 2. Comparison of conventional echocardiographic parameters between studied groups.

\begin{tabular}{|c|c|c|c|c|}
\hline Parameter & $\begin{array}{c}\text { Group (I) } \\
\text { Mean } \pm \text { S.D }\end{array}$ & $\begin{array}{l}\text { Group (II) } \\
\text { Mean } \pm \text { S.D }\end{array}$ & t-test & p-value \\
\hline IVSd (cm) & $0.83 \pm 0.16$ & $0.90 \pm 0.15$ & 2.677 & 0.108 \\
\hline IVSs $(\mathrm{cm})$ & $1.17 \pm 0.28$ & $1.29 \pm 0.21$ & 3.219 & 0.079 \\
\hline LVIDd (cm) & $5.02 \pm 0.61$ & $5.03 \pm 0.37$ & 0.005 & 0.942 \\
\hline LVIDs (cm) & $3.30 \pm 0.51$ & $3.18 \pm 0.37$ & 0.991 & 0.324 \\
\hline LVPWd (cm) & $0.86 \pm 0.16$ & $0.88 \pm 0.15$ & 0.148 & 0.702 \\
\hline $\mathrm{EDV}(\mathrm{ml})$ & $121.64 \pm 33.49$ & $119.45 \pm 18.14$ & 0.279 & 0.781 \\
\hline $\mathrm{ESV}(\mathrm{ml})$ & $47.33 \pm 18.61$ & $40.36 \pm 9.94$ & 2.584 & 0.114 \\
\hline $\mathrm{EF}(\%)$ & $62.91 \pm 7.10$ & $66.32 \pm 5.51$ & 3.614 & 0.063 \\
\hline $\mathrm{SV}(\mathrm{ml})$ & $76.73 \pm 22.44$ & $79.00 \pm 11.40$ & 0.192 & 0.663 \\
\hline FS (\%) & $34.27 \pm 5.21$ & $36.91 \pm 3.73$ & 4.191 & 0.064 \\
\hline $\mathrm{LA}(\mathrm{cm})$ & $4.89 \pm 0.67$ & $3.72 \pm 0.38$ & 54.474 & $0.001^{\star}$ \\
\hline $\mathrm{AO}(\mathrm{cm})$ & $2.80 \pm 0.35$ & $2.92 \pm 0.52$ & 1.002 & 0.321 \\
\hline PASP (mmHg) & $40.09 \pm 8.34$ & $24.09 \pm 5.25$ & 7.993 & $0.001^{\star}$ \\
\hline MVA by PHT $\left(\mathrm{cm}^{2}\right)$ & $1.07 \pm 0.24$ & $3.74 \pm 1.09$ & 345.033 & $0.001^{*}$ \\
\hline $\begin{array}{c}\text { MVA by } \\
\text { Plainmetry }\left(\mathrm{cm}^{2}\right)\end{array}$ & $1.06 \pm 0.23$ & $3.71 \pm 0.63$ & 490.283 & $0.001^{*}$ \\
\hline MV Max PG (mmHg) & $21.19 \pm 6.85$ & $3.56 \pm 1.06$ & 142.741 & $0.001^{\star}$ \\
\hline MV Mean PG (mmHg) & $11.66 \pm 4.76$ & $1.32 \pm 0.45$ & 102.683 & $0.001^{*}$ \\
\hline HR & $81.70 \pm 15.85$ & $80.23 \pm 14.69$ & 0.120 & 0.730 \\
\hline
\end{tabular}

IVSd: diastolic interventricular septum dimension; IVSs: systolic interventricular septum dimension; LVIDd: left ventricular end diastolic dimension; LVIDs: left ventricular end systolic dimension; LVPWd: left ventricular posterior wall dimension; EDV: end diastolic volume; ESV: end systolic volume; EF: ejection fraction; FS: fractional shortening; SV: stroke Volume; AO: aortic root diameter; LA: left atrium diameter, PASP pulmonary artery systolic pressure; $\mathrm{MVA}=$ mitral valve area; $\mathrm{p}$-value $\leq 0.05$ is considered significant; $\mathrm{t}=$ student test. 
Table 3. Comparison of echocardiographic parameters of left atrial appendagebetween studied groups.

\begin{tabular}{|c|c|c|c|c|c|}
\hline & & $\begin{array}{c}\text { Group (I) } \\
\text { Mean } \pm \text { S.D }\end{array}$ & $\begin{array}{l}\text { Group (II) } \\
\text { Mean } \pm \text { S.D }\end{array}$ & t-test & p-value \\
\hline \multicolumn{2}{|c|}{$\begin{array}{l}\text { LAA empting Doppler Flow } \\
\qquad(\mathrm{m} / \mathrm{s})\end{array}$} & $0.33 \pm 0.22$ & $0.53 \pm 0.37$ & 2.515 & $0.015^{*}$ \\
\hline \multicolumn{2}{|c|}{$\begin{array}{l}\text { LAA filling Doppler Flow } \\
\qquad(\mathrm{m} / \mathrm{s})\end{array}$} & $-0.33 \pm 0.21$ & $-0.48 \pm 0.30$ & 2.184 & $0.033^{*}$ \\
\hline \multicolumn{2}{|c|}{ LAA smallest area $\left(\mathrm{cm}^{2}\right)$} & $1.99 \pm 1.18$ & $1.05 \pm 0.33$ & 13.262 & $0.001^{*}$ \\
\hline \multicolumn{2}{|c|}{ LAA largest area $\left(\mathrm{cm}^{2}\right)$} & $3.68 \pm 1.50$ & $2.25 \pm 0.51$ & 18.411 & $0.001^{*}$ \\
\hline \multicolumn{2}{|l|}{ LAA EF (\%) } & $46.73 \pm 13.95$ & $54.22 \pm 10.94$ & 4.493 & $0.039^{*}$ \\
\hline \multicolumn{2}{|l|}{ LAA thrombus (NO \%) } & $39.1 \%$ & $00 \%$ & 1.457 & 0.151 \\
\hline \multirow{4}{*}{$\begin{array}{c}\text { Spontaneous } \\
\text { echo contrast (NO \%) }\end{array}$} & 0 & $0 / 330 \%$ & $14 / 2263.6 \%$ & \multirow{4}{*}{23.88} & \multirow{4}{*}{0.001} \\
\hline & 1 & $16 / 3348.5 \%$ & $8 / 2236.5 \%$ & & \\
\hline & 2 & $9 / 3327.3 \%$ & $0 / 220 \%$ & & \\
\hline & 3 & $8 / 3324.2 \%$ & $0 / 220 \%$ & & \\
\hline
\end{tabular}

LAA $=$ left atrial appendage; $\mathrm{EF}=$ ejection fraction; ${ }^{\star}$ Significant, $\mathrm{p}$-value $\leq 0.05$ is considered significant; $\mathrm{t}=$ student test.

Table 4. Comparison of LAA strain \& strain rate between both groups.

\begin{tabular}{|c|c|c|c|c|c|}
\hline & & $\begin{array}{c}\text { Group (I) } \\
\text { Mean } \pm \text { S.D }\end{array}$ & $\begin{array}{l}\text { Group (II) } \\
\text { Mean } \pm \text { S.D }\end{array}$ & t-test & p-value \\
\hline \multicolumn{2}{|c|}{ Strain of medial wall (\%) } & $11.35 \pm 7.48$ & $19.17 \pm 16.57$ & 2.380 & $0.021^{\star}$ \\
\hline \multicolumn{2}{|c|}{ Strain of latral wall (\%) } & $16.00 \pm 13.39$ & $27.36 \pm 21.84$ & 2.392 & $0.020^{\star}$ \\
\hline \multicolumn{2}{|c|}{ Global strain of LAA (\%) } & $13.67 \pm 7.15$ & $23.26 \pm 13.12$ & 3.499 & $0.001^{*}$ \\
\hline & $\begin{array}{c}\mathrm{RSr} \\
(1 / \mathrm{sec})\end{array}$ & $2.00 \pm 1.04$ & $3.11 \pm 2.20$ & 2.50 & $0.016^{*}$ \\
\hline \multirow[t]{3}{*}{$\begin{array}{l}\text { Strain rate of } \\
\text { medial wall }\end{array}$} & $\begin{array}{c}\mathrm{CSr} \\
(1 / \mathrm{sec})\end{array}$ & $-1.27 \pm 0.61$ & $-2.07 \pm 1.38$ & 8.739 & $0.005^{*}$ \\
\hline & $\begin{array}{c}\mathrm{ASr} \\
(1 / \mathrm{sec})\end{array}$ & $-1.18 \pm 0.96$ & $-2.09 \pm 1.76$ & 6.070 & $0.017^{\star}$ \\
\hline & $\begin{array}{c}\text { RSr } \\
(1 / \mathrm{sec})\end{array}$ & $2.34 \pm 1.47$ & $3.64 \pm 2.47$ & 5.981 & $0.018^{*}$ \\
\hline \multirow[t]{3}{*}{$\begin{array}{l}\text { Strain rate of } \\
\text { lateral wall }\end{array}$} & $\begin{array}{c}\mathrm{CSr} \\
(1 / \mathrm{sec})\end{array}$ & $-1.40 \pm 1.10$ & $-2.99 \pm 1.70$ & 17.759 & $0.001^{*}$ \\
\hline & $\begin{array}{c}\mathrm{ASr} \\
(1 / \mathrm{sec})\end{array}$ & $-1.43 \pm 0.86$ & $-3.28 \pm 2.81$ & 12.588 & $0.001^{*}$ \\
\hline & $\begin{array}{c}\mathrm{RSr} \\
(1 / \mathrm{sec})\end{array}$ & $2.17 \pm 0.93$ & $3.37 \pm 1.82$ & 3.219 & $0.002^{*}$ \\
\hline \multirow[t]{2}{*}{$\begin{array}{l}\text { Global strain } \\
\text { rate of LAA }\end{array}$} & $\begin{array}{c}\mathrm{CSr} \\
(1 / \mathrm{sec})\end{array}$ & $-1.33 \pm 0.67$ & $-2.58 \pm 1.18$ & 25.104 & $0.001^{\star}$ \\
\hline & $\begin{array}{c}\mathrm{ASr} \\
(1 / \mathrm{sec})\end{array}$ & $-1.30 \pm 0.74$ & $-2.69 \pm 1.88$ & 14.920 & $0.001^{*}$ \\
\hline
\end{tabular}

$\mathrm{LAA}=$ left atrial appendage; $\mathrm{RSr}=$ reservoir strain rate; $\mathrm{CSr}=$ conduit strain rate; $\mathrm{ASr}=$ atrial contractile strain rate; ${ }^{\star}$ Significant, $\mathrm{p}$-value $\leq 0.05$ is considered significant; $\mathrm{t}=$ student test. 
Table 5. Correlation between global strain of LAA and other studied variables.

\begin{tabular}{ccc}
\hline \multirow{2}{*}{ Variables } & \multicolumn{2}{c}{ Global strain of LAA } \\
\cline { 2 - 3 } & $\mathrm{r}$ & $\mathrm{p}$ \\
\hline LA diameter & -0.389 & $0.003^{*}$ \\
PASP & -0.328 & $0.015^{*}$ \\
MVA_by_plainmetry & 0.283 & $0.036^{*}$ \\
LAA_+_VE_flow & 0.635 & $0.0001^{*}$ \\
LAA_-_VE_flow & 0.598 & $0.0001^{*}$ \\
LAA_EF & 0.276 & $0.042^{*}$ \\
Contrast_ & -0.309 & $0.021^{*}$ \\
\hline
\end{tabular}

$\mathrm{r}=$ correlation coefficient; $\mathrm{p}$-value $\leq 0.05$ is considered significant; LV_EF: Ejection Fraction of Left Ventricle; LA: Left Atrium Diameter; PASP: Pulmonary Artery Systolic Pressure; LVEDD: Left Ventricular End Diastolic Diameter; MVA: Mitral Valve Area; LAA: Left Atrial Appendage; Contrast: Degree of Spontaneous Contrast in LAA; *: Significant Correlation.

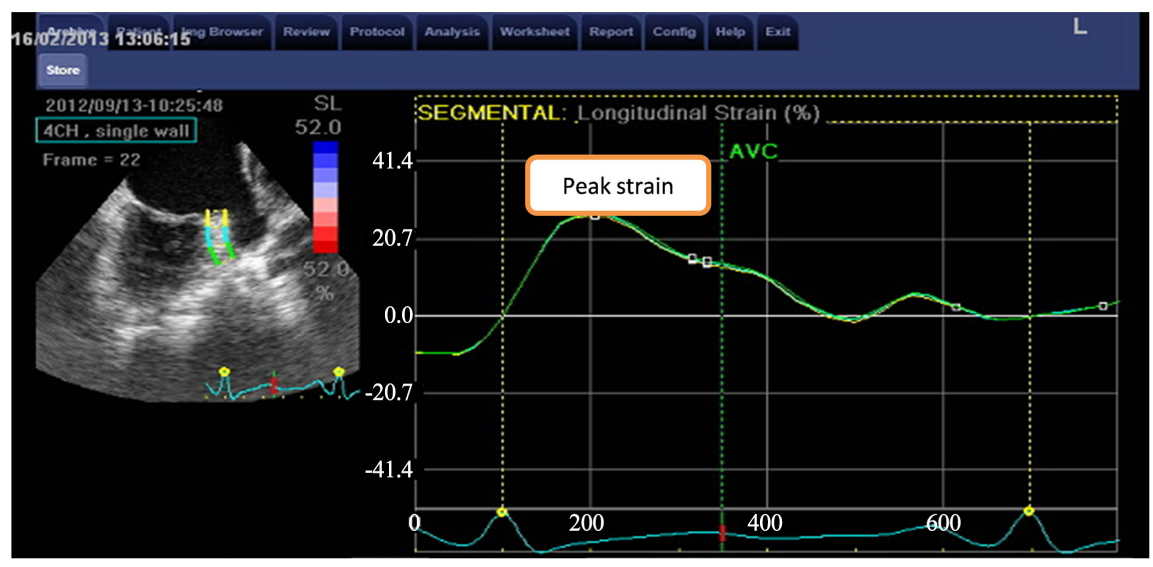

Figure 1. Strain of medial wall in a control person No. 4, average peak strain was $35 \%$.

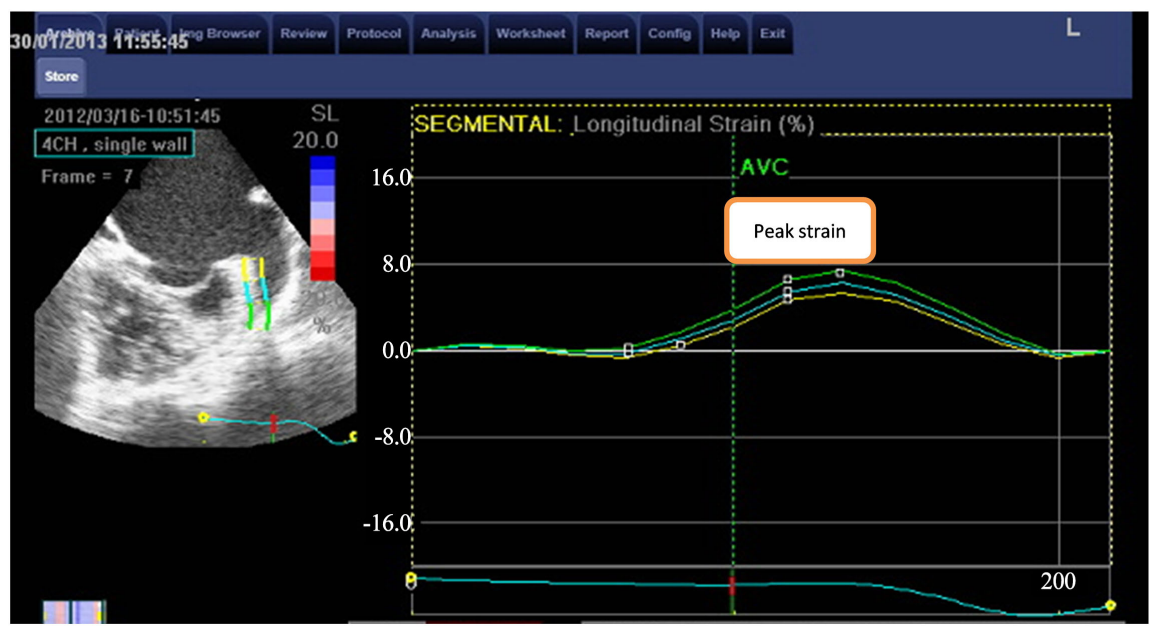

Figure 2. Strain of the medial wall of the LAA in patient with MS (MVA $1.1 \mathrm{~cm}$ ), average peak strain was $6.9 \%$. 


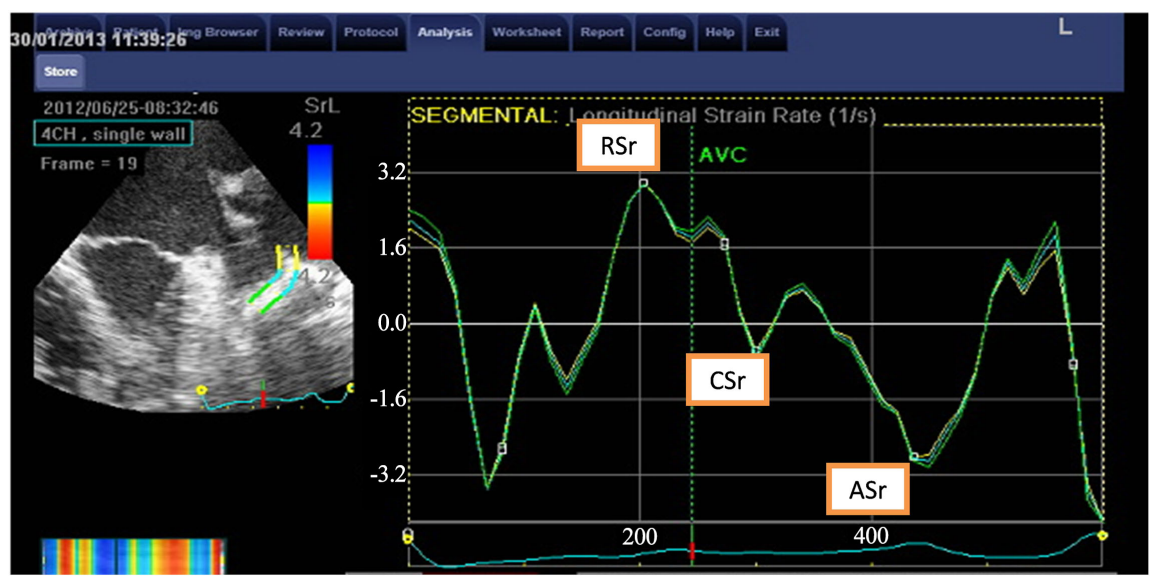

Figure 3. Strain rate of patient NO $5($ MVA $1.2 \mathrm{~cm}), \mathrm{RSr}=$ reservoir strain rate, $\mathrm{CSr}=$ conduit strain rate, and $\mathrm{ASr}=$ atrial contractile strain rate.

\section{Discussion}

Mitral stenosis is one of the common causes that affect the function of LA and LAA. This may be due to the significant increase in left atrial pressure caused by after load elevation [1], also the contractile dysfunction of LAA may be due to inflammatory process of rheumatic disease that affect the endocardium and myocardium of left atrial appendage [6].

In this study we found that as regards to the conventional echocardiography there were higher LA diameter, LAA smallest \&largest area's and lowered LAA $\mathrm{EF}$ in patient group than control, this is due to increased left atrial pressure to maintain blood flow through the stenotic valve and over a period, mitral stenosis and persistently raised LA pressure result in LA \& LAA dilatation and subsequently dysfunction [7].

This comes in agreement with Gorbasi et al. [8] who found that LAA largest area in mitral stenosis with sinus rhythm and normal subjects was $5.3 \pm 2.2 \mathrm{~cm}$ vs. $2.4 \pm 0.5 \mathrm{~cm}^{2}$ in control, and LAA ejection fraction of was $50 \% \pm 16 \%$ in patients group and $70 \% \pm 7 \%$ in normal subjects respectively.

Similar results reported also by Topsakal et al. [9] who reported that patients with mitral stenosis had significantly decreased LAA ejection fraction compared to normal subjects ( $39 \% \pm 14 \%$ vs. $69 \% \pm 13 \%)$ respectively.

As regarding LAA emptying and filling velocities we found that patients group had significantly decreased LAA emptying and filling velocities than control persons.

Hemodynamically significant MS increases the resistance to both passive and active LAA emptying, resulting in lowering of LAA flow velocities, regardless of the specific rhythm [10]. Direct LAA and LA involvement in the rheumatic inflammatory process, and an atrial myopathy resulting from chronic LA pressure elevation, are additional possibilities [11].

We found that there was no statistically significant difference between the two groups as regard to presence of thrombus ( $p$ value 0.151 ) although there was 3 patients in our study had thrombus within LAA, but the degree of SEC is more 
advanced in case group (SEC grade II \& III present only in patients group). This can be explained as left atrial appendage active blood flow and contractile function may be disturbed even in sinus rhythm due to elevated left atrial pressure caused by afterload elevation, contractile dysfunction may cause blood stasis in the LAA cavity and this might be one of the mechanisms for formation of SEC and thrombus in left atrial appendage [1].

In this study LAA longitudinal strain and strain rate were lower in patients group,

Saracoglu et al. [12] reported that Longitudinal Strain of LAA of normal subjects in sinus rhythm and patients with AF and it was (19.2\% $\pm 6.8 \%$ vs. $7.4 \% \pm$ $3.4 \%)$ and Global Longitudinal reservoir strain rate (RSr) $\left(2.5 \pm 1.0 \mathrm{~s}^{-1}\right.$ vs. $1.1 \pm$ $\left.0.6 \mathrm{~s}^{-1}\right)$, similar results also found by Rendón et al. [13] who reported Global Longitudinal Strain of LAA of normal subjects in sinus rhythm and patients with AF and it was (17\% vs. $5.7 \%$ ), and Global Longitudinal reservoir strain rate (RSr) (3.1 vs. 0.9). our study show decrease in all values of strain and strain rate in patients with mitral stenosis in sinus rhythm, it was $(13.67 \% \pm 7.15 \%)$ for Global Longitudinal Strain of LAA and $(2.17 \pm 0.93 \%,-1.33 \pm 0.67,-1.30 \pm$ $0.74)$ for Global Longitudinal reservoir strain rate (RSr), Global Longitudinal conduit strain rate (CSr), Global Longitudinal atrial contractile strain rate (ASr) respectively. Although all our study patients are in sinus rhythm but the results of their strain and strain rate are similar to the results of patients with AF obtained from the previously mention studies [12] [13] denoting that the mitral stenosis decrease the function and contractility of left atrial appendage markedly. Various studies found thatat the time of mitral valvotomy Aschof nodules are present in a large number in left atrial appendages, mainly at the sub endocardial tissue [6].

Rohani et al. [14] found that the peak systolic global LA strain acutely improved post-balloon mitral valvuloplasty $(\mathrm{p}<0.001)$ and after mitral valve replacement $(\mathrm{p}=0.012)$. This difference was statistically highly significant.

Many studies assessed the LA function by STE in sinus and AF rhythm and they found that the AF alone even with non-valvular affection and with CHA2DS2-VASc risk score zero has marked impairment of LA function [15], Shaikh et al. [16] found that mean peak LA strain was lower in patients with AF as compared to the control group. Further confirmation was given by Mochizuki et al. [17] who found that peak LA strain was reduced in patients with paroxysmal AF compared with controls, and further reduction was observed in patients with permanent $\mathrm{AF}$

Our study found that global longitudinal strain (GLS) was negatively correlated with LA diameter, PASP and contrast degree and positively correlated with MVA, LAA filling and emptying velocities and LA EF.

This is explained by as mitral stenosis develops there will be elevated left atrial pressures that will transmitted to the pulmonary vasculature and causes pulmonary hypertension, in long standing mitral stenosis the persistent elevation in left atrial pressure leads to remodeling and dilatation of left atrial appendage, with 
deterioration of the systolic and diastolic functions, there will be more stagnation and stasis of the blood within LAA with more higher degree of SEC and liability for thrombus formation [18] [19] and this come in agreement of the study of Sevimli et al. [20] who reported that the Strain and strain rate values were significantly lower in patients with spontaneous echocardiographic contrast when compared with those without spontaneous echocardiographic contrast (strain; $2.42 \pm 0.98$ vs. $13.1 \pm 5.9, \mathrm{p}<0.001$ and strain rates wave $0.97 \pm 0.54$ vs. $3.34 \pm$ $1.15, \mathrm{p}<0.001)$ respectively.

\section{Conclusion}

2D speckle tracking strain and strain rate of LAA is a feasible technique and is significantly reduced in patients with mitral stenosis even with sinus rhythm denoting impairment of the mechanical function of LAA even with sinus rhythm.

\section{Clinical Implication}

Strain imaging assess the LAA mechanical function directly and not indirectly as the volumetric method and this can help in discover early disease affection and progression. Therefore, the noninvasive assessment of LAA longitudinal deformation may add incremental information for predicting the occurrence LAA thrombi and the development of atrial fibrillation or response to therapy.

\section{Limitations}

We faced in this Study limitations which included: First: A small sample size included in the study as most patients with mitral stenosis develop AF and our study included patients in sinus rhythm only, Second we used the LV software for calculation of LA strain parameters as until now; there is no available specific atrial software.

\section{Conflicts of Interest}

The authors declare no conflicts of interest regarding the publication of this paper.

\section{References}

[1] Al-Saady, N.M., Obel, O.A. and Camm, A.J. (1999) Left Atrial Appendage Structure, Function, and Role in Thromboembolism. Heart, 82, 547-554. https://doi.org/10.1136/hrt.82.5.547

[2] Pollick, C. and Taylor, D. (1991) Assessment of Left Atrial Appendage Function by Transesophageal Echocardiography. Implications for the Development of Thrombus. Circulation, 84, 223-231. https://doi.org/10.1161/01.CIR.84.1.223

[3] Nucifora, G., Faletra, F.F., Regoli, F., et al. (2011) Evaluation of the Left Atrial Appendage with Real-Time 3-D Transesophageal Echocardiography: Implications for Catheter-Based Left Atrial Appendage Closure. Circulation: Cardiovascular Imaging, 4, 514-523. https://doi.org/10.1161/CIRCIMAGING.111.963892 
[4] Bansal, M. and Kasliwal, R.R. (2012) Echocardiography for Left Atrial Appendage Structure and Function. Indian Heart Journal, 64, 469-475. https://doi.org/10.1016/j.ihj.2012.07.020

[5] Bansal, M. and Kasliwal, R.R. (2013) How Do I Do It? Speckle-Tracking Echocardiography. Indian Heart Journal, 65, 117-123.

https://doi.org/10.1016/j.ihj.2012.12.004

[6] Chopra, P. and Gulwani, H. (2007) Pathology and Pathogenesis of Rheumatic Heart Disease. Indian Journal of Pathology and Microbiology, 50, 685-697.

[7] Mittnacht, A.J., Fanshawe, M. and Konstadt, S. (2008) Anesthetic Considerations in the Patient with Valvular Heart Disease Undergoing Noncardiac Surgery. Seminars in Cardiothoracic and Vascular Anesthesia, 12, 33-59.

[8] Gölbaşi, Z., Ciçek, D., Canbay, A., Uçar, O., Bayol, H. and Aydogdu, S. (2002) Left Atrial Appendage Function in Patients with Mitral Stenosis in Sinus Rhythm. European Journal of Echocardiography, 3, 39-43.

https://doi.org/10.1053/euje.2001.0110

[9] Topsakal, R., Eryol, N.K., Ozdogru, I. and Seyfeli, E. (2003) Color Doppler Tissue Imaging to Evaluate Left Atrial Appendage Function in Patients With Mitral Stenosis in Sinus Rhythm. Echocardiography, 20, 29-35. https://doi.org/10.1046/j.1540-8175.2003.00004.x

[10] Agmon, Y., Khandheria, B.K., Gentile, F. and Seward, J.B. (1999) Echocardiographic Assessment of the Left Atrial Appendage. Journal of the American College of Cardiology, 34, 1867-1877. https://doi.org/10.1016/S0735-1097(99)00472-6

[11] Lee, T.M., Chou, N.K. and Su, S.F. (1996) Left Atrial Spontaneous Echo Contrast in Asymptomatic Patients with a Mechanical Valve Prosthesis. The Annals of Thoracic Surgery, 62, 1790-1795. https://doi.org/10.1016/S0003-4975(96)00739-4

[12] Saraçoğlu, E., Ural, D., Şahin, T., et al. (2013) Assessment of Left Atrial Appendage Function by 2-Dimensional Speckle-Tracking Imaging in Transesophageal Echocardiography. JACC, 62, 465.

[13] Rendón, J.A. and Duarte, N.R. (2014) Assessment of Left Atrial Appendage Function by Speckle Tracking. Revista Colombiana de Cardiologia, 21, 154-159.

[14] Rohani, A., Kargar, S., Fazlinejad, A., Ghaderi, F., Vakili, V., Falsoleiman, H., et al. (2017) Acute Effect of Treatment of Mitral Stenosis on Left Atrium Function. Annals of Cardiac Anaesthesia, 20, 42-44. https://doi.org/10.4103/0971-9784.197832

[15] Ahmed, M.K., Abdelazez, W.F. and Nasif, M.A. (2015) Assessment of Left Atrium Mechanical Function by Deformation Imaging in Atrial fibrillation and Its Correlation with CHA2DS2-VASc Risk Score. The Egyptian Heart Journal, 67, 209-215. https://doi.org/10.1016/j.ehj.2014.08.001

[16] Shaikh, A.Y., Maan, A., Khan, U.A., Gerard, P., et al. (2012) Speckle Echocardiographic Left Atrial Strain and Stiffness Index as Predictors of Maintenance of Sinus Rhythm after Cardioversion for Atrial Fibrillation: A Prospective Study. Cardiovascular Ultrasound, 10, 10-48.

[17] Mochizuki, A., Yuda, S., Oi, Y., Kawamukai, M., Nishida, J., et al. (2013) Assessment of Left Atrial Deformation and Synchrony by Three-Dimensional Speckle-Tracking Echocardiography: Comparative Studies in Healthy Subjects and Patients with Atrial Fibrillation. Journal of the American Society of Echocardiography, 26, 165-174. https://doi.org/10.1016/j.echo.2012.10.003

[18] Tomotsugu, T., Takashi, O. and Nobuo, F. (1996) Influence of Left Atrial Pressure on Left Atrial Appendage Flow Velocity Patterns in Patients in Sinus Rhythm. Journal of the American Society of Echocardiography, 9, 857-864. 
https://doi.org/10.1016/S0894-7317(96)90478-2

[19] Ozer, N., Can, I., Atalar, E., Sade, E., Aksoyek, S. and Ovunc, K. (2004) Left Ventricular Long-Axis Function Is Reduced in Patients with Rheumatic Mitral Stenosis. Echocardiography, 21, 107-112. https://doi.org/10.1111/j.0742-2822.2004.03064.x

[20] Sevimli, S., Gundogdu, F., Arslan, S., Aksakal, E. and Gurlertop, H.Y. (2007) Strain and Strain Rate Imaging in Evaluating Left Atrial Appendage Function by Transesophageal Echocardiography. Echocardiography, 24, 823-829.

https://doi.org/10.1111/j.1540-8175.2007.00469.x 